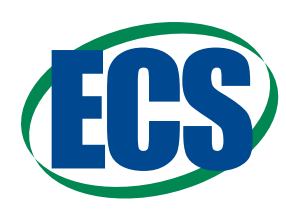

\title{
Dynamic Neutron Imaging and Modeling of Cationic Impurities in Polymer Electrolyte Water Electrolyzer
}

\author{
Mateusz Zlobinski, ${ }^{1, *}$ (1) Ugljesa Babic, ${ }^{1}$ Meriem Fikry, ${ }^{1}$ Lorenz Gubler, ${ }^{1, * *}$ (i) Thomas \\ J. Schmidt, ${ }^{1,2, * * *}$ and Pierre Boillat ${ }^{1,3, z}$ \\ ${ }^{1}$ Electrochemistry Laboratory, Paul Scherrer Institute, 5232 Villigen PSI, Switzerland \\ ${ }^{2}$ Laboratory of Physical Chemistry, ETH Zurich, 8093 Zurich, Switzerland \\ ${ }^{3}$ Laboratory of Neutron Scattering and Imaging, Paul Scherrer Institute, Villigen PSI, Switzerland
}

\begin{abstract}
The high operation and capital costs of polymer electrolyte water electrolyzers (PEWE) are the major obstacles that have to be tackled for hydrogen to penetrate the market as a solution for renewable energy storage. Commercial stacks often suffer from cationic contamination of catalyst-coated membranes (CCMs) that comes from impure feed water and corrosion of system components, which can result in increasing operation costs and lowered lifetime. This study describes the behavior of the contaminants in the CCMs and their impact on performance under various operating conditions using $\mathrm{Gd}^{3+}$ as model contaminant imaged with neutron with a combination of high effective temporal $(2 \mathrm{~s})$ and spatial $(30 \mu \mathrm{m})$ resolutions. The presence of electric field directly affects the position of cations in the CCM leading to their accumulation near the cathode catalyst layer. The cationic impurities trigger multiple loss mechanisms, as the ohmic resistance increase does not scale linearly with the amount of occupied exchange groups in the membrane (10\% resistance increase caused by $2.5 \%$ exchange groups occupation). A model has been developed that predicts the movement of the ions in the CCM under intermittently operating PEWE and was used as a basis to explain the hysteresis observed in the polarization curve of contaminated PEWEs.

(c) 2020 The Author(s). Published on behalf of The Electrochemical Society by IOP Publishing Limited. This is an open access article distributed under the terms of the Creative Commons Attribution 4.0 License (CC BY, http://creativecommons.org/licenses/ by/4.0/), which permits unrestricted reuse of the work in any medium, provided the original work is properly cited. [DOI: 10.1149/ $1945-7111 / \mathrm{abc} 83 \mathrm{~b}]$
\end{abstract}

Manuscript submitted August 4, 2020; revised manuscript received September 18, 2020. Published November 17, 2020.

Water electrolysis is considered a key technology for the conversion of fluctuating electricity from renewable energy sources in large-scale storage applications. Renewable $\mathrm{H}_{2}$ can be used to decarbonize the traditionally carbon-intensive mobility and chemical industry sectors. ${ }^{1}$ Only about $6 \%$ of $\mathrm{H}_{2}$ is currently produced using water electrolysis, ${ }^{2}$ since the other production methods are at the moment still more cost-effective (e.g. steam methane reforming, coal gasification, partial oxidation of methane etc.). ${ }^{3-7}$ Market penetration of water electrolyzers will only be possible if the techno-economical aspect is fully resolved. Although significant effort is put into reducing the stack cost and substituting or restricting the use of precious metals, ${ }^{8-24}$ the end-cost of $\mathrm{H}_{2}$ produced by water electrolysis is dominated by the cost of electricity. ${ }^{25}$ Through polymer electrolyte water electrolyzers (PEWE), nowadays, $\mathrm{H}_{2}$ can be produced at high rates (2.5 tons per day from a $5 \mathrm{MW}$ stack) and relatively high voltage efficiency $(70 \%-80 \%)^{26,27}$ by employing thin membranes $(<200$ micron). Furthermore, $\mathrm{H}_{2}$ can be produced at high pressure (10-300 bar), ${ }^{4,28-30}$ reducing the costs associated with $\mathrm{H}_{2}$ drying and compression. $^{31}$

Catalyst coated membranes (CCMs) used for PEWE are susceptible to contamination by water impurities $\left(\mathrm{Ca}^{2+}, \mathrm{Cu}^{2+}, \mathrm{Ni}^{2+}, \mathrm{Pb}^{2+}\right.$, $\mathrm{Fe}^{3+}, \mathrm{Ti}^{2+}$ etc.) that may be present in the anodic feed water as a result of corrosion of system components or user contamination. ${ }^{32-36}$ Cationic impurities occupy the ion exchange sites in the CCM and reduce the voltage efficiency of the PEWE, thereby directly increasing the cost of produced hydrogen. Furthermore, Fentonactive transition metal ions may promote chemical degradation of the ionomer, additionally lowering the lifetime of the PEWE stack. ${ }^{37}$ Contamination has been identified as a major contributor to the voltage degradation in a long-term perspective and therefore numerous studies have been carried out to investigate the influence of the cation presence in the proton exchange membrane $(\mathrm{PEM})^{32-35,38}$ as well as mitigation strategies. ${ }^{39}$ In our previous study, we have shown the distribution of Gd-ions in the CCM cross- section using operando neutron imaging, from which regeneration strategies have been derived. ${ }^{36}$ It has been shown that in situ generated carbonic acid made by flowing $\mathrm{CO}_{2}$ gas through the gas water separator can be used to remove cationic impurities from the CCM and thereby successfully recover the performance of the cell. Such strategies prolong the overall lifetime of the stack and help to avoid a costly disassembly procedure to exchange CCMs when the cationic contamination is too high to operate the electrolyzer economically.

One of the key findings from our previous article was that the reversible degradation of the CCM could be identified by measuring the polarization curve in two directions (cycling the current), resulting in a cell voltage hysteresis in case of a cation contaminated CCM. A stronger electric field drives the cationic contaminants towards the cathode, resulting in high occupancy of ion exchange sites in the cathode ionomer relative to the membrane. Lowering the electric field (reducing the cell potential, e.g. at low current densities) results in a dominating diffusion-driven movement of the contaminant towards the membrane and the anode catalyst layer. The balance between the two, here termed "electro-diffusion" (see Fig. 1) determines the concentration profile of the contaminant in the CCM cross-section.

This study investigates the magnitude of the two driving forces, associated to diffusion and migration of the cationic impurities in the CCM using Gadolinium (III) as a model cation. For the first time, dynamic operando neutron imaging is used to determine the transient position of the ionic contaminants in the CCM cross-section and correlates it to the cell voltage losses. In conjunction with imaging data, the diffusion and migration coefficients of $\mathrm{Gd}^{3+}$ ions in the membrane were obtained. We present a model that predicts the electro-diffusion of cations in the CCM under intermittent operation of the cell, which have been validated with experimental data. Finally the model was supplied with the $\mathrm{Fe}^{3+}$ diffusion and migration coefficients and the outcome was compared with the result of our previous study, ${ }^{36}$ successfully linking the position of the cations with the high frequency resistance hysteresis in contaminated PEWE.

\footnotetext{
*Electrochemical Society Student Member.

**Electrochemical Society Member.

****Electrochemical Society Fellow.

${ }^{\mathrm{z}}$ E-mail: pierre.boillat@psi.ch
} 


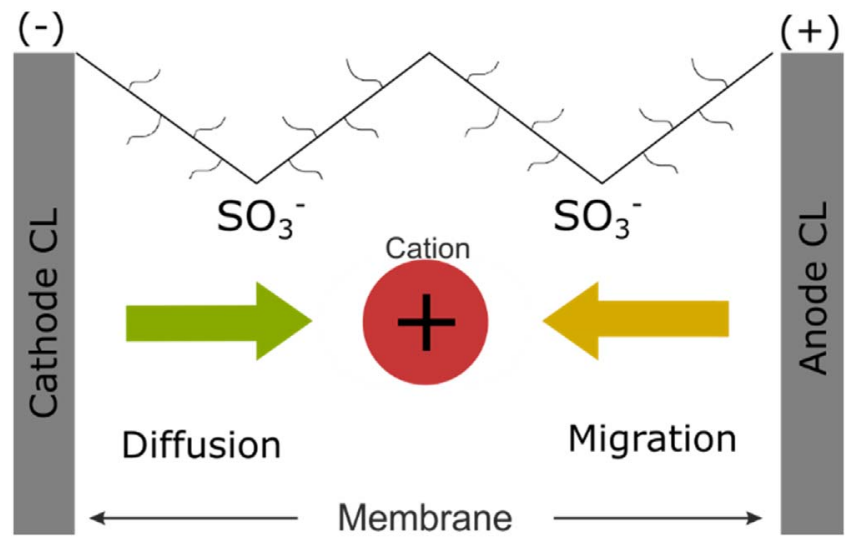

Figure 1. Schematic representation of the presence of a contaminant cation in the catalyst coated membrane, and its qualitative distribution along the cross-section coordinate at $\mathrm{OCV}$ and increasing cell voltage. The combined effect of migration under the effect of the electric field and diffusion because of a concentration gradient determines the concentration profile of nonproton cations.

\section{Experimental}

Materials and components.-A custom-made cell assembled with commercial N117 CCM supplied by Greenerity $\left(2 \mathrm{mg} \mathrm{cm}^{-2}\right.$ $\mathrm{Ir} / \mathrm{O}_{2}$ on the anode and $1 \mathrm{mg} \mathrm{cm}^{-2} \mathrm{Pt} / \mathrm{C}$ on the cathode side) with an active area of $1 \mathrm{~cm}^{2}$ and Sika T10 sintered titanium porous transport layers (PTLs) delivered by GKN. Detailed information on these particular PTLs can be found elsewhere. ${ }^{40}$ Before assembly, the PTLs were treated in an ultra-sonication bath in ultrapure water (18 $\mathrm{M} \Omega \mathrm{cm}$ ) for $2 \mathrm{~h}$. The CCMs were assembled in dry state, the cell was then filled with water, heated up to $50{ }^{\circ} \mathrm{C}$ and conditioned for the total duration of $3 \mathrm{~d}$ under intermittent operating conditions by varying between $\mathrm{OCV}$ and $1 \mathrm{~A} \mathrm{~cm}^{-2}$. The contaminated feed water was obtained by dissolving $\mathrm{Gd}_{2}\left(\mathrm{SO}_{4}\right)_{2}$ (Sigma Aldrich) in $\mathrm{D}_{2} \mathrm{O}$ with an isotopic purity of $99 \%$ in a ratio that finally gives the concentration of $0.5 \mathrm{mmol} \mathrm{l}^{-1}$. The flow fields were made out of gold coated stainless steel with five $1 \mathrm{~mm} \times 1 \mathrm{~mm}$ straight channels separated by $1 \mathrm{~mm}$ of lands.

Neutron imaging setup.-The experiments have been carried out at the POLDI neutron diffractometer beamline ${ }^{41}$ at the SINQ facility which has been modified accordingly in order to allow neutron imaging measurements. A tilted detector and anisotropic collimation $^{42}$ were used in order to push the limits of spatial resolution in the direction of interest. The final pixel size was $5 \mu \mathrm{m}$ and the effective resolution was $30 \mu \mathrm{m}$ in the direction of magnification. A $10 \mu \mathrm{m}$ thick scintillator screen made of $\mathrm{D}_{2} \mathrm{O}_{2} \mathrm{~S}$ was used as a detector and placed in a tilted position so that its surface formed a $10^{\circ}$ angle with the beam axis. The resulting light was collected through a system of two mirrors and a commercial optical lens (Zeiss Makro Planar T100) and recorded by a scientific CMOS camera (Andor Marana). The exposure times varied from $0.2 \mathrm{~s} /$ image to $20 \mathrm{~s} / \mathrm{image}$ depending on the experimental phase. Postprocessing included filtering, grouping and normalization of the images. The reference conditions were chosen to be wet anode $\left(\mathrm{H}_{2} \mathrm{O}\right.$ or $\mathrm{D}_{2} \mathrm{O}$ depending on the measurement phase) and dry cathode in order to avoid possible artifacts coming from membrane swelling due to water uptake.

Gadolinium proved to be a representative model cation in terms of electrochemical behavior according to our previous study. ${ }^{36}$ Thanks to its very high neutron cross-section of Gd atoms (over 300 times more than that of a water molecule) good contrast can be obtained while maintaining reasonably low concentration of contaminants in the CCM. An in-house developed mobile test bench and custom designed electrochemical cell have been used to perform experiments. Due to the high attenuation coefficients of water, gadolinium and the membrane, it was necessary to use $\mathrm{D}_{2} \mathrm{O}$ instead of $\mathrm{H}_{2} \mathrm{O}$ in order to avoid signal saturation. In general, the experiment can be divided into four phases: $\mathrm{H}_{2} \mathrm{O}$ to $\mathrm{D}_{2} \mathrm{O}$ transition, contamination, dynamic movement of cations and regeneration, all conducted while collecting neutron radiograms.

Electrochemical measurements methods and conditions.-The study presented here comprises neutron imaging of $\mathrm{Gd}^{3+}$ movement within the CCM, synchronized with two separate electrochemical data acquisition systems; one being a commercial potentiostat allowing accurate cell characterization, and the other an in-house developed data acquisition system capable of measuring the voltage and current at high frequencies $(50 \mathrm{kHz})$. During the experiments the cell was operated at a constant voltage of $2 \mathrm{~V}$ and impedance spectra were continuously measured $(10 \mathrm{kHz}$ to $100 \mathrm{mHz})$. The only exceptions are periods when the polarization curves were being recorded and when the impact of intermittent operation was investigated. Impedance spectra and IV-curves were measured using a Biologic SP-300 potentiostat with a built in 10 A booster, while the intermittent start-stop operation was carried out using a DC electronic load (Itech IT8511). The thermal conditions were ascertained by controlling the cell temperature, feed tank temperatures and by using heating tubes with integrated temperature sensors. While switching between feed loops the cell outlet was connected to a waste tank to ensure that there is no cross-contamination between the vessels.

Experimental procedure.-At first, the cell was operated intermittently for $3 \mathrm{~d}$ on ultrapure water in order to ensure stable performance, characterize the cell and ensure that the CCM is well conditioned. Once the baseline had been established, the transition to heavy water started by switching the feed to the respective vessel and guiding the fluid from the outlet of the cell to the waste tank for a short period of time to ensure that all $\mathrm{H}_{2} \mathrm{O}$ has been drained out from the system, after which the loop was closed again. Once the performance of the cell running on $\mathrm{D}_{2} \mathrm{O}$ had stabilized, the feed was switched to the contaminated loop and the accumulation of the $\mathrm{Gd}^{3+}$ in the CCM was observed. Once the current density at a given voltage $(2 \mathrm{~V}$ ) dropped to $\sim 70 \%$ of the initial value, the feed loop was switched back to fresh water to prevent further contamination. After the cell reached steady state, start-stop protocols were introduced during which dynamic electro-migration of $\mathrm{Gd}^{3+}$ ions was observed. The final step of the experiment was the regeneration of the cell by injecting dilute sulfuric acid $\left(0.5 \mathrm{mmol}^{-1}\right)$ in the cathode cell compartment.

During the experiments, two conditions were be enforced, one where the current was applied when the ions were distributed evenly in the membrane, and a second one where the current was turned off when the equilibrium between the migration and diffusion forces were already established. These two cases were then repeated one after the other to establish constant movement of the ions within the CCM. The initial conditions for both cases are shown graphically in Fig. 2.

Ionic movement modeling and validation.-Mass transport of ions in the electrolyte can be broken down into three basic mechanisms: diffusion, migration and convection. Different forces drive each of these mechanisms. Diffusion is caused by a gradient in species concentration $\nabla c$ and the migration by the potential gradient $\nabla \phi$, i.e. the electric field. Last but not the least, the convective forces are associated with bulk movement of the electrolyte. The flux equation can be written as follows:

$$
J_{\text {total }}=\underbrace{-D_{i} \cdot \frac{\partial c_{i}}{\partial x}}_{\text {diffusion }}-\underbrace{u_{m} \cdot c_{i} \cdot \frac{\partial \varphi}{\partial x}}_{\text {migration }}+\underbrace{c_{i} \cdot v}_{\text {convection }}
$$

Where $D_{\mathrm{i}}$ represents the diffusion coefficient $\left(\mathrm{cm}^{2} \mathrm{~s}^{-1}\right), c_{\mathrm{i}}$ local concentration of ions $\left(\mathrm{mol} \mathrm{cm} \mathrm{cm}^{-3}\right), x$ is the coordinate across the 
a)

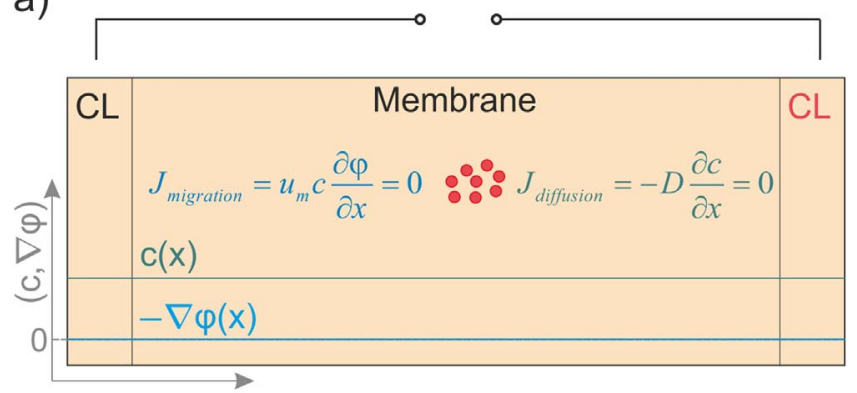

b)
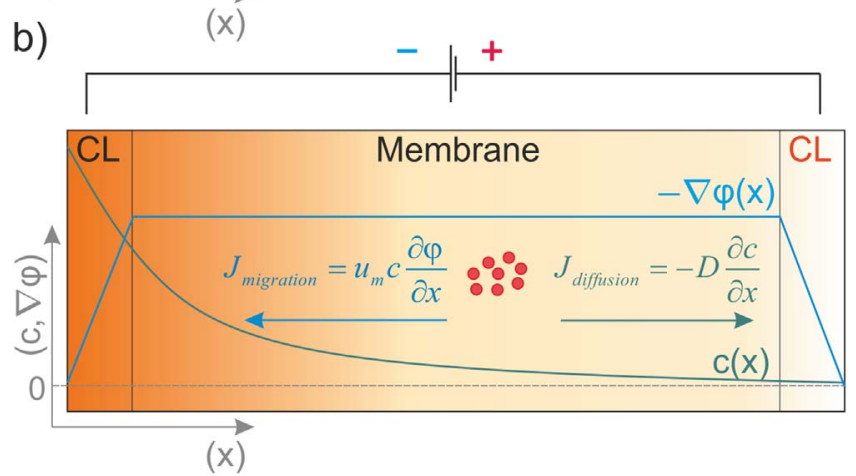

Figure 2. Simplified schematic of cation concentration and electric field distribution across CCM cross-sections with the forces that act on positively charged ions under (a) OCV and (b) operating conditions.

electrolyte $(\mathrm{cm}), u_{\mathrm{m}}$ the ionic mobility $\left(\mathrm{cm}^{2} \mathrm{~V}^{-1} \mathrm{~s}^{-1}\right), \phi$ the electric potential $(\mathrm{V})$ and the $v$ the bulk flow rate of the electrolyte $\left(\mathrm{cm} \mathrm{s}^{-1}\right)$.

Since the PEM is a solid electrolyte, the convective term can be omitted in this study. The mobility $u_{\mathrm{m}}$ was calculated using the Nernst-Einstein equation, which links it with the diffusion coefficient:

$$
u_{m}=\frac{D_{i} \cdot z \cdot e}{k \cdot T}
$$

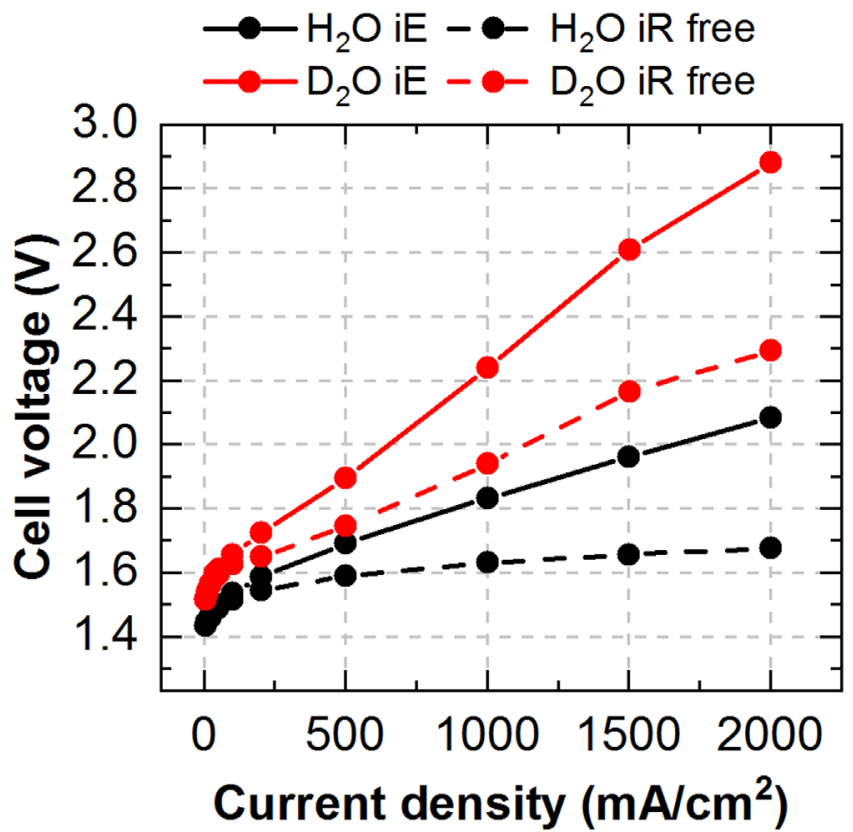

Figure 3. Measured and Ohmic resistance corrected (iR-free) polarization curves of the electrolyzer running on $\mathrm{H}_{2} \mathrm{O}$ (black) and $\mathrm{D}_{2} \mathrm{O}$ (red), measured at $50{ }^{\circ} \mathrm{C}$.
Where $z$ represents the ion valence $(-), e$ the elementary charge $(\mathrm{C})$, $k$ the Boltzmann constant $\left(\mathrm{J} \cdot \mathrm{K}^{-1}\right)$. and $T$ the temperature $(\mathrm{K})$.

Based on the mentioned equations, a model was developed to simulate the transport properties of multivalent ions in the CCM. The diffusion coefficient was set as a variable parameter and the simulation was iterated until the results from calculations, and experiments converged. Two scenarios were simulated, where one served as a correlating run and the second one as validation. In the first situation the electrolyzer is turned on after a long idling period, which means that both diffusion and migration forces will be in effect. The second situation, the electrolyzer is suddenly turned off and only diffusion is in effect, which will lead to the collapse of the concentration profile established previously during operation, leading to even distribution of the cations in the CCM. The case when the electrolyzer is turned on after a period of idling has been simulated first, as the boundary conditions for this situation can be easily extracted from experimental data (average concentration of cations in the CCM). The outcome of the first simulation provided a steady-state concentration profile, which served as an input for the next calculation run when the electrolyzer is suddenly turned off and only diffusion forces are acting. To summarize the first simulation $(\mathrm{OFF} \rightarrow \mathrm{ON})$ the transport coefficients were set to a value that will return the transient results matching the experiments. Next, the output from the first simulation was fed to the second run $(\mathrm{ON} \rightarrow$ OFF), and the simulation was crosschecked with another experiment in order to validate the results.

\section{Results and Discussion}

Transition from light water to heavy water.-Due to the high neutron cross-section and relatively high water thickness in the direction of the beam, it was necessary to replace normal water with heavy water to avoid signal saturation. ${ }^{43}$ This way, it was possible to achieve good contrast between $\mathrm{Gd}^{3+}$ ions and the wet CCM. Replacement of $\mathrm{H}_{2} \mathrm{O}$ by $\mathrm{D}_{2} \mathrm{O}$ was found to significantly affect the performance of the cell as seen on Fig. 3. Major contribution to the overpotential increase is not related to the membrane transport only, since the HFR corrected polarization curves $\left(\mathrm{HFR}_{\mathrm{H} 2 \mathrm{O}}=202 \mathrm{~m} \Omega\right.$ $\left.\mathrm{cm}^{2}, \mathrm{HFR}_{\mathrm{D} 2 \mathrm{O}}=304 \mathrm{~m} \Omega \mathrm{cm}^{2} @ 1 \mathrm{~A} \mathrm{~cm}^{-2}\right)$ are still separated from each other by a significant amount $\left(310 \mathrm{mV} @ 1 \mathrm{~A} \mathrm{~cm}^{-2}\right)$.

Remaining losses that were unaccounted for come from slightly different physical properties of light and heavy water and their different kinetic behavior. ${ }^{44}$ Detailed analysis of the $\mathrm{D}_{2} \mathrm{O}$ fed electrolyzer and its voltage loss breakdown is not the focus of this study, therefore further performance drop investigation has not been included in the study. Impact of $\mathrm{D}_{2} \mathrm{O}$ injection was observed with both electrochemical and neutron imaging methods. Exchange of the water in PTLs was relatively quick (circa $9 \mathrm{~min}$ ), but in order to exchange a significant amount in the membrane, over $3 \mathrm{~h}$ of operation on the $\mathrm{D}_{2} \mathrm{O}$ feed were necessary (Fig. 4). Thorough image processing revealed that a very slow exchange process, which was not apparent in electrochemical profiles and not possible to notice without complete analysis, was still ongoing throughout all the experiments. This fact has its own implications regarding further data analysis, and will be brought to the reader's attention in respective paragraphs. As far as slow isotope exchange in the membrane is concerned, it appears that diffusion is not the limiting mechanism in the exchange since in the PTL no concentration gradient can be observed across its thickness. The CCM was therefore in direct contact with pure $\mathrm{D}_{2} \mathrm{O}$ and the mass transport driven by diffusion would be expected to be relatively fast.

Contamination and regeneration.-Exchange between heavy and light water can be observed by a sharp signal intensity increase because of $\mathrm{D}_{2} \mathrm{O}$ low neutron cross section. Once the transition from $\mathrm{H}_{2} \mathrm{O}$ to $\mathrm{D}_{2} \mathrm{O}$ was complete, the contamination using $0.5 \mathrm{mmol} \mathrm{l}^{-1}$ $\mathrm{Gd}_{2}\left(\mathrm{SO}_{4}\right)_{2}$ in $\mathrm{D}_{2} \mathrm{O}$ was initiated. Figure 5 shows the process of cell performance degradation and the appearance of $\mathrm{Gd}^{3+}$ over time. The cell was operated potentiostatically at $2 \mathrm{~V}$ to ensure the safe 
a)

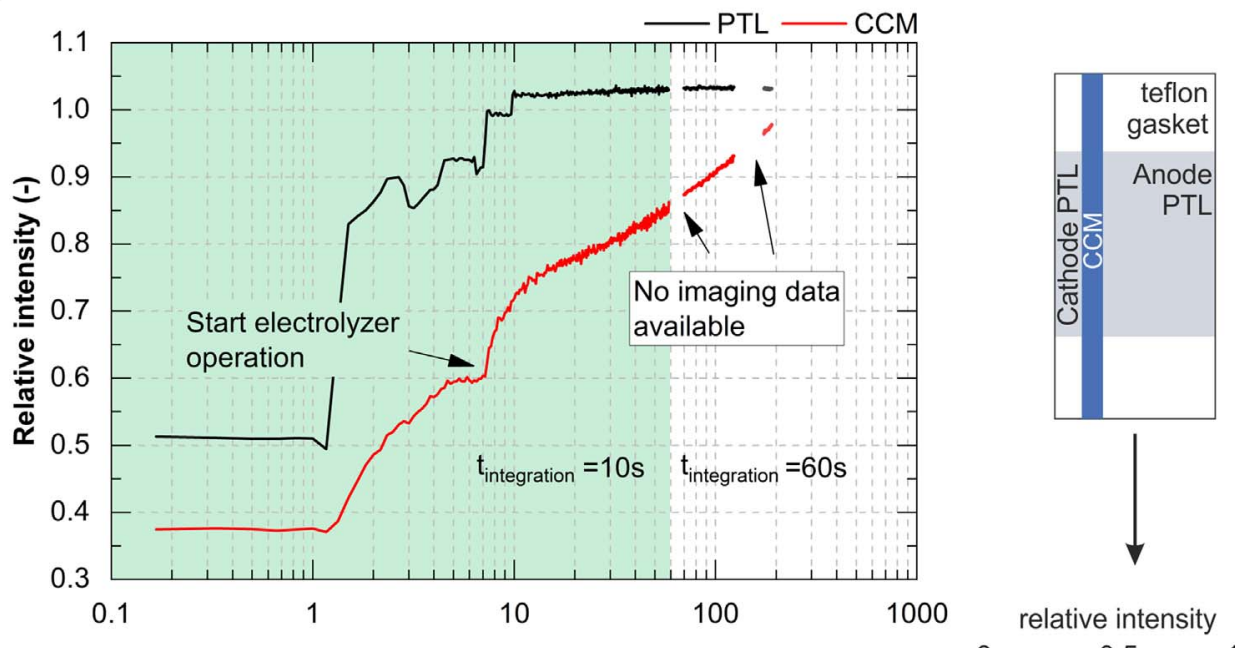

b)

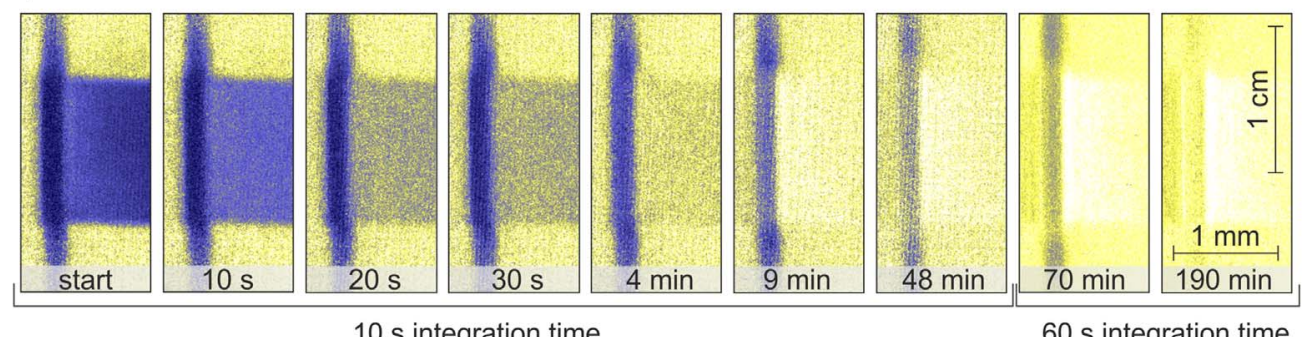

Figure 4. (a) Average relative neutron transmission intensity in the anode PTL and $\mathrm{CCM}$ as a function of time representing the transition from $\mathrm{H}_{2} \mathrm{O}$ to $\mathrm{D}_{2} \mathrm{O}$, (b) respective neutron radiographs.

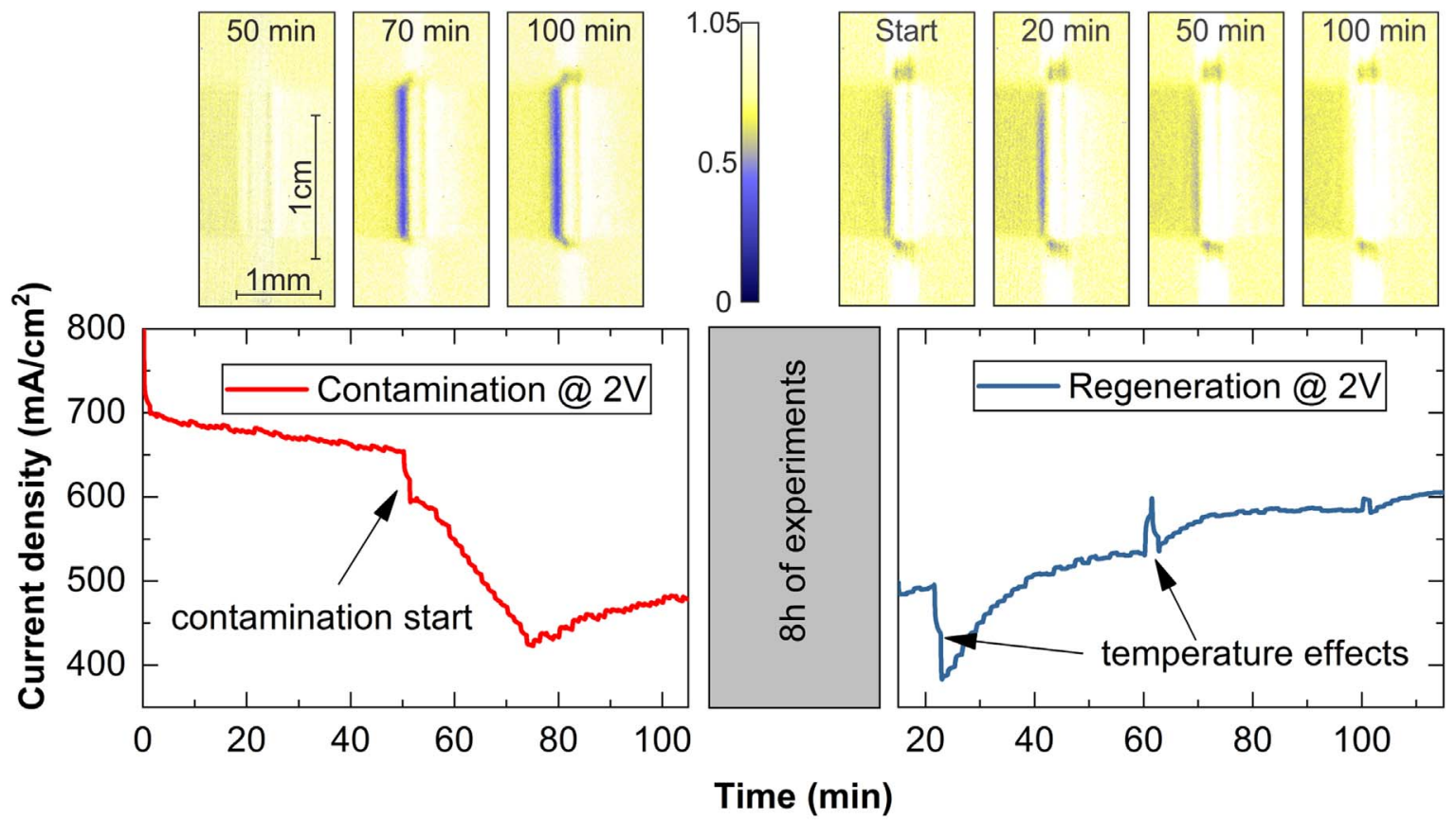

Figure 5. Current density profile over time of the cell operated at constant potential set to $2 \mathrm{~V}$ for contamination and regeneration processes.

operation during all experiments that will result in significant performance loss and would otherwise risk triggering the overvoltage safety limits of the power supply unit.

After $\sim 50$ min of operation on fresh $\mathrm{D}_{2} \mathrm{O}$ the steady state was reached and the contaminant was introduced leading to a rapid drop in current density. After $\sim 20 \mathrm{~min}$, the current density reached a value of $\sim 70 \%$ with respect to the reference case. At this point, the feed loop was switched back to the fresh $\mathrm{D}_{2} \mathrm{O}$ to ensure that no more contaminants were supplied to the CCM. Recovery of the voltage is immediately observed as the contaminant cations are moving to 
positions near the cathode catalyst layer where the impact of their presence is less severe. ${ }^{36}$ When the electrochemical conditions reached steady state ( $\sim 30$ min from switch to the fresh feed loop) all transient experiments were carried out, which took approximately $8 \mathrm{~h}$. The last step of the experiment included operando regeneration of the electrolyzer by introducing dilute $\mathrm{H}_{2} \mathrm{SO}_{4}$ acid $\left(0.5 \mathrm{mmol}^{-1}\right)$ to the cathode cell compartment. Initially, a drop of the performance can be seen due to a temperature effect after the acid (which was at room temperature) was injected. The first $\sim 10 \mathrm{~min}$ show the contribution of both heating up of the cathode solution and the regeneration, but once the current density passed the $500 \mathrm{~mA} \mathrm{~cm}^{-2}$ mark it can be assumed that from that point on the only phenomena affecting the recovery of the cell are those attributed to the ion exchange between CCM and sulfuric acid. In addition, imaging data shows the disappearance (Fig. 5) of the accumulated gadolinium ions near the cathode catalyst layer, confirming the regeneration process. The regeneration was not complete due to the time constraints during the measurements in the beamline, but the results clearly show the impact and dynamics of the contaminant removal.

Contamination severity assessment.-Reference images, which have been measured over a relatively long period of time (10 min), allowed calculating the average concentration of the $\mathrm{Gd}^{3+}$ ions in the CCM using Beer-Lambert's law with variable attenuation coefficient dependent on the concentration to account for the beam hardening effects. Assuming that cations are evenly distributed in the CCM, the average concentration was calculated to be $9.4 \cdot 10^{-6} \mathrm{~mol} \mathrm{~cm}^{-3}$. In order to put this value into perspective, it has to be compared with the ion exchange capacity (IEC) of Nafion, which was previously reported to be $1.3 \cdot 10^{-3} \mathrm{~mol} \mathrm{~cm}^{-3}$. 45 The IEC was divided by a factor of 3 to account for the multivalence of the gadolinium cations and the maximum physically possible concentration of $\mathrm{Gd}^{3+}$ ions in the membrane is therefore $4.3 \cdot 10^{-4} \mathrm{~mol} \mathrm{~cm}^{-3}$. Finally, the ratio of contaminants in the membrane and potentially available exchange groups was obtained and yielded roughly $2.5 \%$ while the HFR at $50 \mathrm{~mA} \mathrm{~cm}^{-2}$ increased by approximately $10 \%\left(\mathrm{HFR}_{\text {cont }}=0.35 \Omega \mathrm{cm}^{2} ; \mathrm{HFR}_{\text {clean }}=0.31 \Omega\right.$ $\mathrm{cm}^{2}$ ). Nonlinearity of the HFR increase with the reduction of exchange sites could be explained by possible complex interactions with polymer due to presence of multivalent ions, which would branch together different side chains. This additional interaction may affect the structure of the polymer itself and result in the observed over-proportional increase of HFR. However, in order to resolve the exact mechanism and influence of multivalent ion presence in the polymer network however, a separate study would be necessary.

Electro-diffusion within the CCM under intermittent operating conditions.- It has been shown that the cationic impurities accumulate close to cathode catalyst layer under the effect of the electric field forming a band of increased resistance. ${ }^{36}$ As already mentioned, this work expands the study with transient phenomena by providing periodic intermittency in the power profile. Moreover, the optimization of the experimental setup allowed resolving the concentration profiles inside the membrane. Figure 6 illustrates that alternating between shutdown and operation of the cell influences the position of the cations in the CCM.

The exposure time of each frame was set to $0.5 \mathrm{~s}$ but during postprocessing, the images underwent a time binning and grouping procedure. This reduced the temporal resolution to $2 \mathrm{~s}$, which proved to be sufficient. To present the transient data in a more comprehensive way the intensity profiles across the CCM have been plotted for various time points for shutdown and startup cases in Fig. 7.

In Fig. 7, the $x$-axis represents the distance from the center of the CCM cross-section. The relative intensity on the $y$-axis means that all the results have been normalized to the case where the cations are already present in the CCM and are evenly distributed. Such processing was necessary due to the ongoing $\mathrm{D}_{2} \mathrm{O}$ exchange with the $\mathrm{H}_{2} \mathrm{O}$ that originally filled the CCM, which introduced artifacts and features in the profiles that made the analysis difficult to present in absolute transmission. On the other hand, data shown in this particular way are very suitable for highlighting the shifts from the equilibrium, which was the main goal of this experiment. The curves have been color coded where red color always shows the steady state profile while the electrolyzer is operating and when the cations are pushed towards the cathode catalyst layer. The deep violet color shows the steady state when the electrolyzer is idling and the ions are evenly distributed in the CCM. The asymmetry in the redistribution time of $\mathrm{Gd}^{3+}$ ions for each direction of current change is evident. It takes one order of magnitude less time to reach steady state for the startup than for the shutdown procedure, because the rate of diffusion slows down as the concentration gradient gradually decreases over time. It is also evident that with normal operating conditions the migration forces are far stronger than the diffusive ones, which results in a very steep concentration profile appearing near of the catalyst cathode layer.

Modeling of ion transport in a membrane of an electrolyzer.Using data on transient transport properties obtained empirically is a good starting point for a qualitative study and transport coefficient calculations. The 1-D model comprises the membrane region and cathode catalyst layer region, which vary in ion exchange capacity and tortuosity. It is assumed that the domain is closed on both ends meaning that the total amount of contaminants in the CCM does not change. The electric field $-\frac{\partial \varphi}{\partial x}$ in the membrane is constant and decays linearly over the thickness of the catalyst layer as shown on Fig. 2. The diffusion and migration equations were solved numerically using a finite differences approximation. The simulation was iterated with a variable diffusion coefficient until the time between the steady state of OFF $\rightarrow$ ON case converged with the empirical data. The steady state concentration profile from previous runs was then fed to the next calculation as initial condition but this time no power was delivered to the cell. The outcome from the simulation is presented on Fig. 8.

Simulation shows that with the amount of contaminants that have been introduced into the CCM, the catalyst layer would be completely filled with $\mathrm{Gd}^{3+}$ ions while the bulk of the membrane would be almost free of Gd-ions while operating. Such situation is however hard to imagine as this would most likely result in incapability of further operation of the cell. Whatever happens in the catalyst layer however is too complex and our model cannot make any further predictions. Tapping into the catalyst layer to get more hints on transient phenomena is also not possible with current state of the art neutron imaging techniques. The time constant however fits the experimental data reasonably well. Therefore, we conclude that the diffusion coefficient of $\mathrm{Gd}^{3+}$ in Nafion is roughly $D_{\mathrm{i}}=8.9 \cdot 10^{-7} \mathrm{~cm}^{2} \mathrm{~s}^{-1}$. In order to put this value into perspective the diffusion coefficient for $\mathrm{Ce}^{3+}$ has been already determined and, assuming the same conditions, is equal to $7.2 \cdot 10^{-7} \mathrm{~cm}^{2} \mathrm{~s}^{-1}{ }^{46}$ Both ions are of the same valence, electron configuration and similar mass $\left(m_{\mathrm{Ce}}=140.1 \mathrm{u} ; m_{\mathrm{Gd}}=157.25 \mathrm{u}\right)$ supporting the results. In order to represent better the correlation between simulation and experiment, the average transmission as a function of time for chosen regions in the CCM have been plotted together in Fig. 9.

The curves representing the bulk of the CCM are correlating well while the cathode catalyst layer ones feature the same trend but the slope is significantly different. The disagreement in this region can possibly be attributed to more complicated transport mechanism, which has not been considered in our simulations. Another factor that has major influence on the results at the catalyst layer and PTL interface is related to the neutron imaging setup. The geometric blur in the images results in an overlap of PTL and CL signals, which is particularly evident in the case where the resolution is not good enough to resolve the whole structure (3 pixels per catalyst layer).

IV curve simulation and HFR hysteresis.-In our previous publication, which focused mostly on the impact of contaminants on electrochemical performance, ${ }^{36}$ it has been shown that for contaminated membranes a very distinct hysteresis in the HFR appears when 

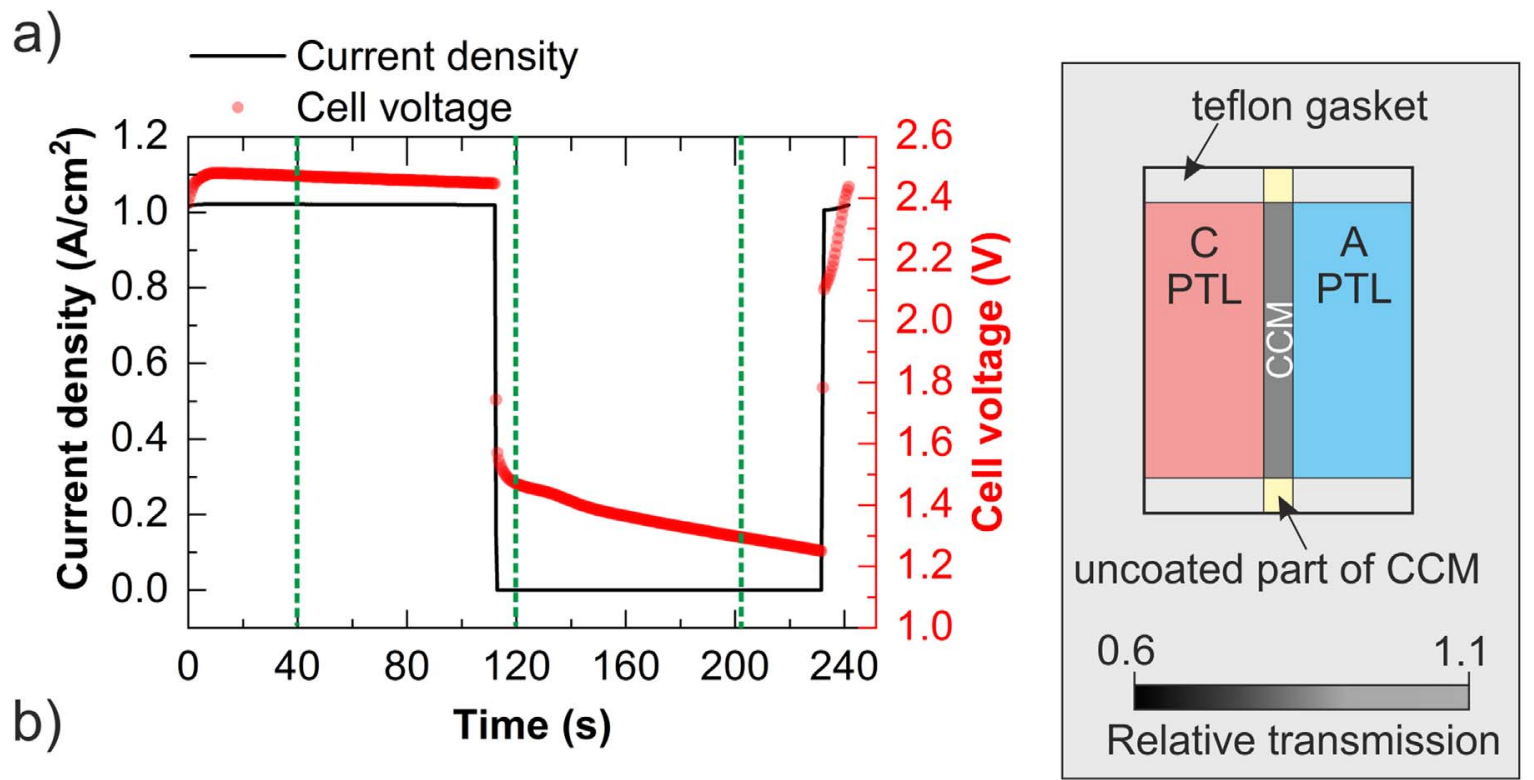

\section{ref images integration time 10min}
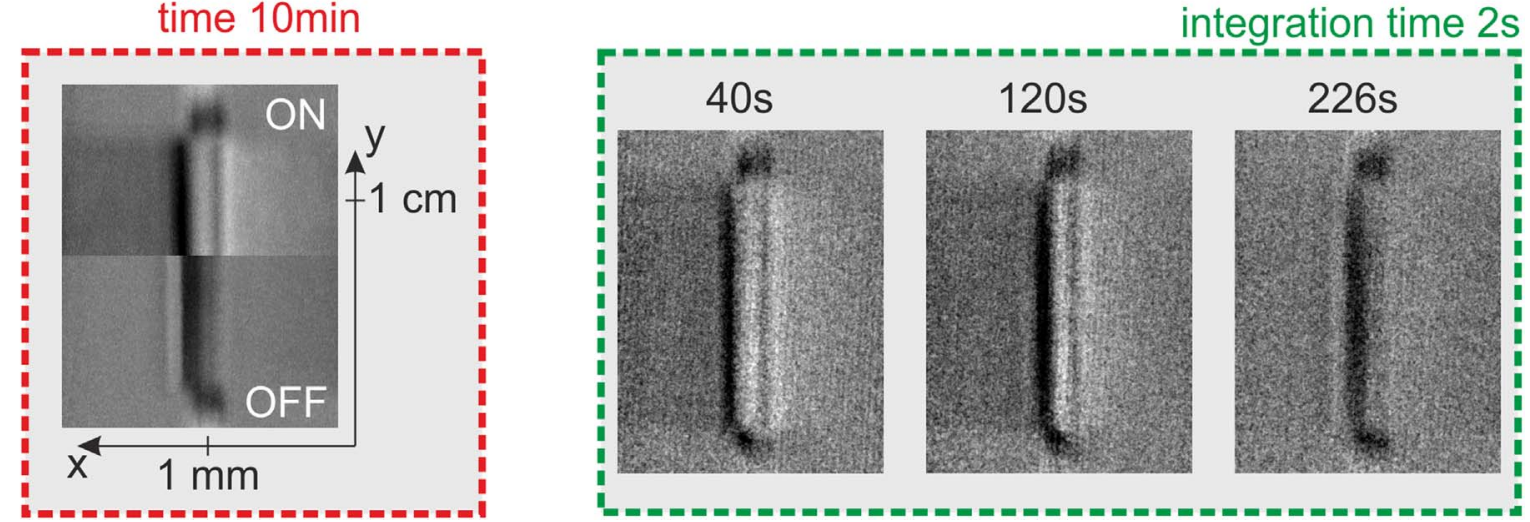

Figure 6. Current density step function for ON-OFF measurements with respective radiographs and reference images.

a)

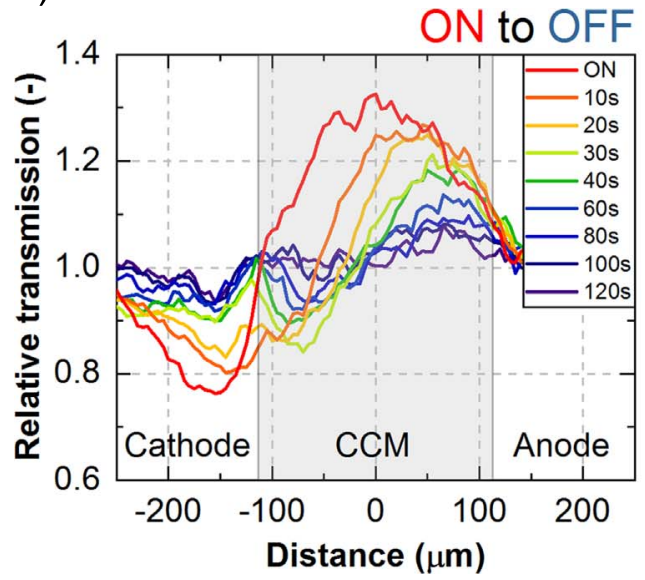

b)

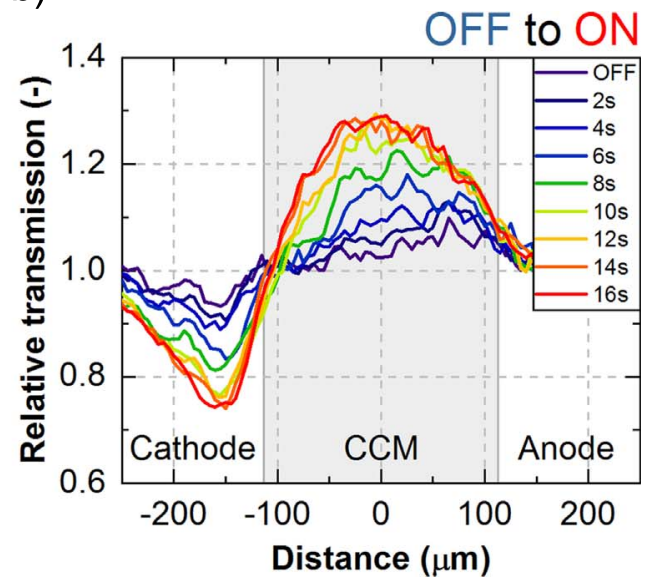

Figure 7. Relative transmission profiles across the CCM during (a) shutdown and (b) start up of the contaminated electrolyzer. The red curve depicts steady state when the ions are accumulated near cathode catalyst layer and deep violet shows the steady state when the cations are evenly distributed in the membrane.

measuring Current-Voltage (IV) curves with ascending and descending current densities in cycles. Using the model that has been validated with experimental data, we inserted new transport parameters that match $\mathrm{Fe}^{3+}$. The amount of contaminants was left the same as the contamination procedure followed an identical protocol and we expect that the cation uptake should not vary significantly as the rate of contamination with $\mathrm{Fe}^{3+}$ and $\mathrm{Gd}^{3+}$ was already shown to be similar to each other. ${ }^{36}$ The diffusion coefficient however was adjusted according to literature ${ }^{47}$ and set to $D_{\mathrm{i}}=2 \cdot 10^{-7} \mathrm{~cm}^{2} \mathrm{~s}^{-1}$. The potential profile from the IV curve measurement was 

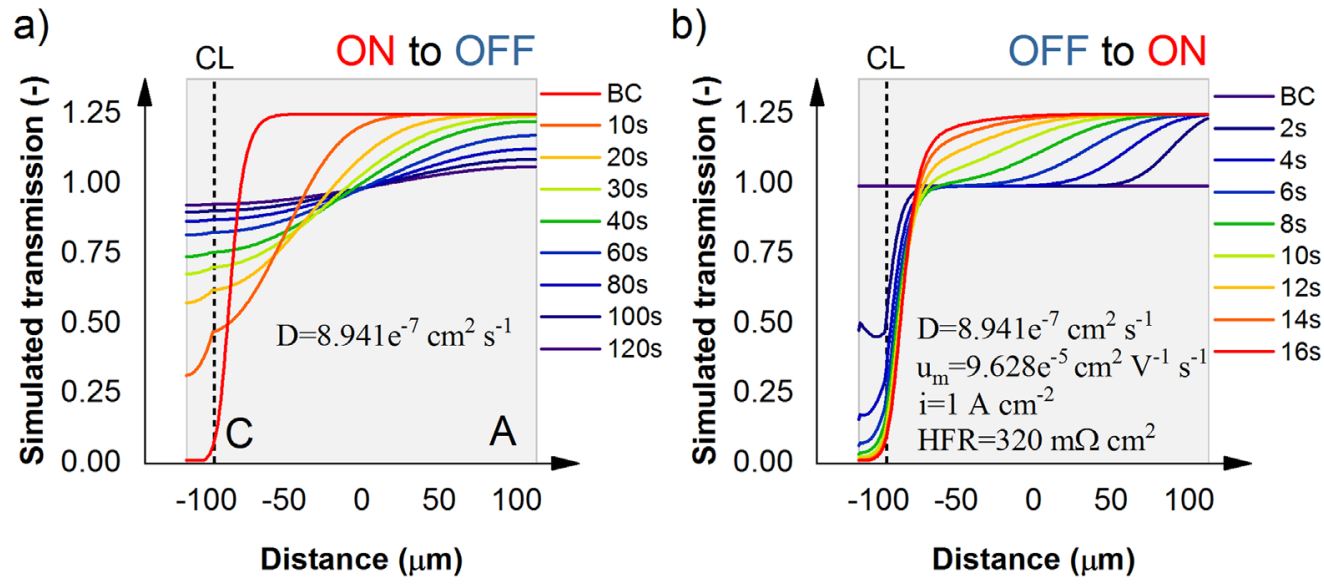

Figure 8. Simulated transmission profiles showing the distribution of the cations in time across the CCM (cathode on the left side, anode on the right) corresponding to respective experimental conditions, (a) shutdown and (b) startup of the cell.
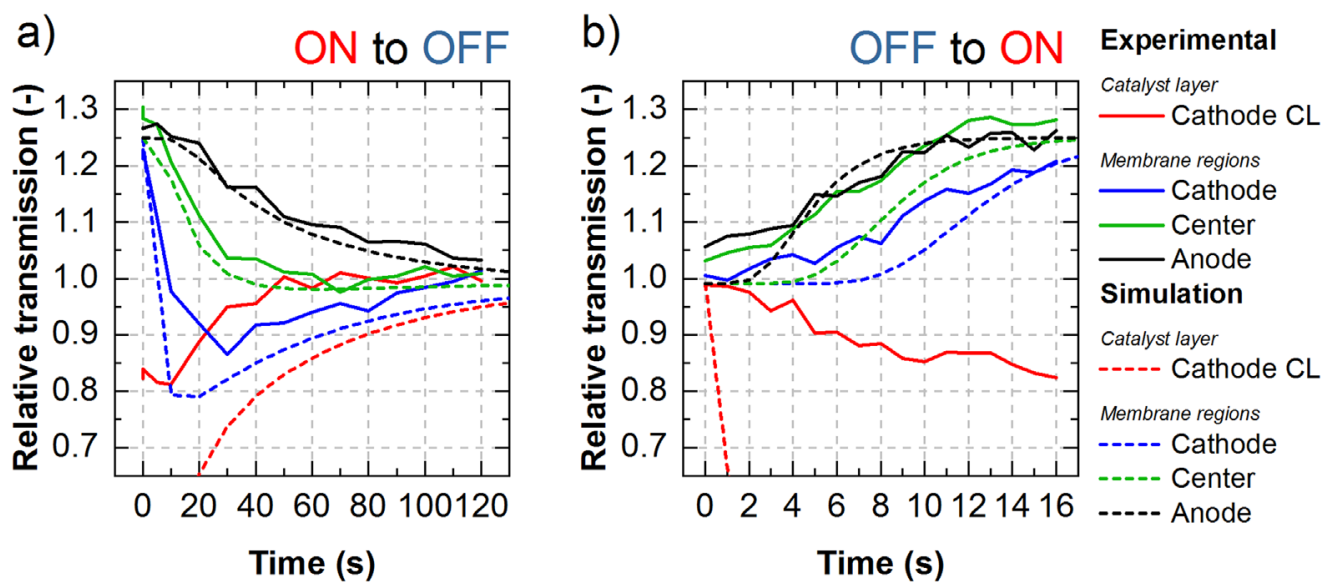

Figure 9. Average relative transmission over time for selected regions of the CCM for experimental data (solid lines) and simulation (dashed lines) corresponding to $\mathrm{Gd}^{3+}$ ion presence for (a) shutdown and (b) startup of the electrolyzer.

reproduced in the simulation and plotted. Figure 10 displays the HFR hysteresis data from the previous study ${ }^{36}$ on the left $y$-axis and the level of contamination of the bulk of the membrane on the right $y$-axis. Since the previous and current study used the same contamination protocol, we assume that contamination levels were reasonably close to each other.

Even distribution of the contaminants within the membrane was set as an initial condition for the simulation, which is why there is a tail above the hysteresis loop on the graph. The total time of the IV curve (up-scan and down-scan) was $225 \mathrm{~s}$, which was too short for the contaminants to fully diffuse back, which returns this particular shape. What has to be noted once again is that a very low content of contaminants in the membrane (2.5\% of CCM capacity) resulted in a large HFR swing $\left(\sim 0.2 \Omega \mathrm{cm}^{2}\right)$. We believe that the presence of multivalent ions in the polymer network has more serious implications than simply occupation of the exchange sites that could be otherwise used for transport of the protons. More research in this direction is necessary.

\section{Conclusions}

The transient behavior of trivalent cationic contaminants in the CCM under intermittent electrolyzer operation has been investigated in the frame of transport properties in the membrane and impact on performance of the cell. During cell operation under commonly used conditions, cations are quickly $(\sim 16 \mathrm{~s})$ pushed to the cathode catalyst layer and occupy a significant share of it. When the cell is turned off, the cations are diffusing back into the bulk of the

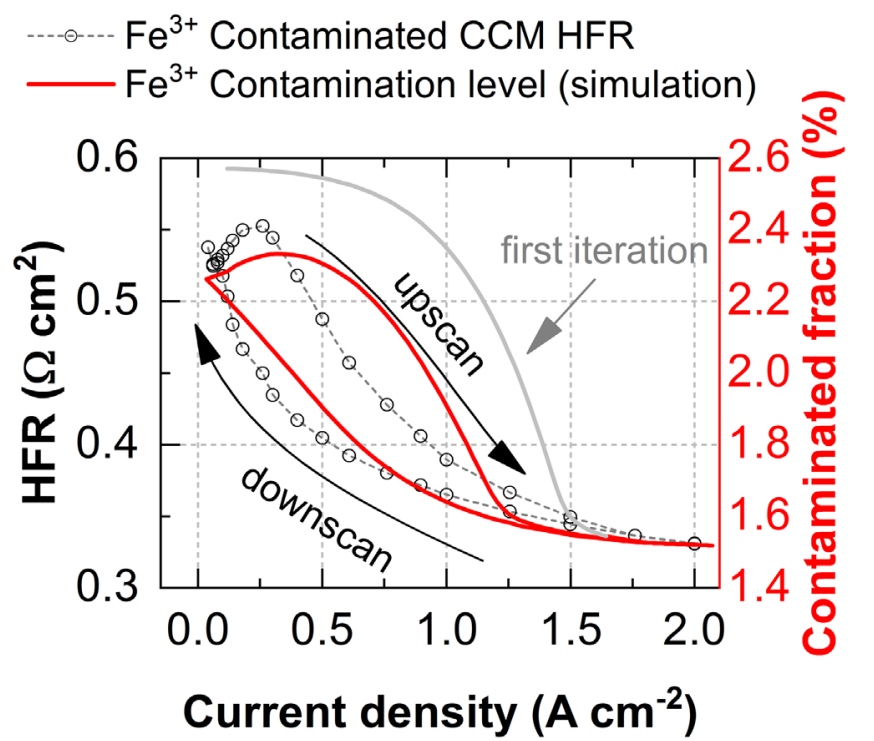

Figure 10. HFR measurements recorded during IV curve measurement during our previous investigation which focused on electrochemical performance loss breakdown due to presence of multivalent cations (black line and empty symbols) and simulated amount of cations in the bulk of the membrane during IV curve measurements (red line) represented as fraction of occupied exchange groups and membrane trivalent ion uptake capacity. 


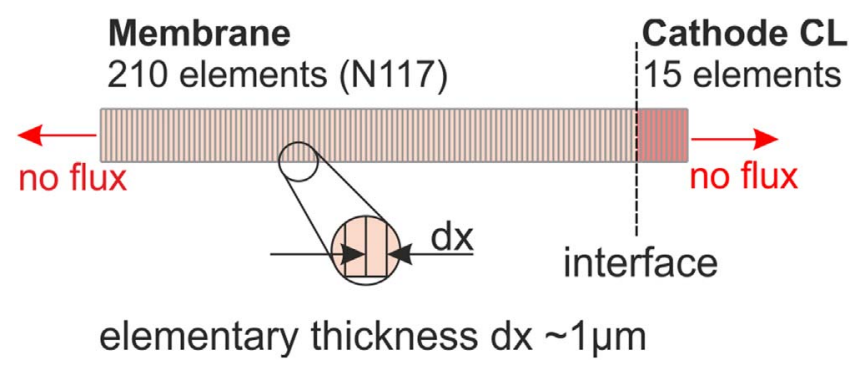

Figure 11. Graphical representation of 1D model geometry used in simulations.

membrane relatively slowly (over $120 \mathrm{~s}$ ). The total amount of $\mathrm{Gd}^{3+}$ model cations in the CCM has been calculated from their resulting change in neutron transmission, indicating that very low concentrations of multivalent impurities in the membrane $(\sim 2.5 \%)$ have a large impact on the performance, possibly due to the more complex mechanisms within polymer network imposed by multivalent cations. A model simulating the movement of the $\mathrm{Gd}^{3+}$ inside the membrane has been developed and, together with experimental data, enabled calculation of the diffusion coefficient $\left(D_{i}=8.9 \cdot 10^{-7} \mathrm{~cm}^{2}\right.$ $\left.\mathrm{s}^{-1}\right)$ and ionic mobility $\left(\mathrm{u}_{\mathrm{m}}=2.9 \cdot 10-5 \mathrm{~cm}^{2} \mathrm{~V}^{-1} \mathrm{~s}^{-1}\right)$ coefficient in the CCM. The result is relatively close to the one of the $\mathrm{Ce}^{3+}$ ion which had been previously determined experimentally. ${ }^{46}$ Upon validation of the model, the movement of $\mathrm{Fe}^{3+}$ cations in the CCM during the IV curve measurement was simulated and compared against the data from our previous study that focused on electrochemical effects associated with the presence of cationic impurities in the membrane. ${ }^{36}$ The average amount of cationic species in the bulk of the membrane during the IV curve measurement reproduces the shape of the HFR hysteresis, which has been previously observed. This result highlights the promise that measurement of IV curves in a cyclic pattern multiple times or other transient techniques (e.g. impedance spectroscopy) could be used for the early detection of contamination with metal cations.

\section{Acknowledgments}

Financial support from the Swiss Federal Office of Energy (SFOE), grant ELY-DEG SI/501198-01 is gratefully acknowledged. TJS thanks Innosuisse and the Swiss Competence Center for Energy Research (SCCER) Heat \& Electricity Storage. The authors kindly acknowledge Oxford Instruments for providing the Andor camera, which was used to record the neutron images.

\section{Appendix}

The appendix contains additional information on the 1D ion transport model that was used to simulate cation movement in the proton exchange membrane. Main assumptions, governing equations and boundary conditions are given below.

As previously mentioned the convection part in the transport equation is considered to be negligible therefore, Eq. 1 takes form:

$$
J_{\text {total }}=\underbrace{-D_{i} \cdot \frac{\partial c_{i}}{\partial x}}_{\text {diffusion }}-\underbrace{u_{m} \cdot c_{i} \cdot \frac{\partial \varphi}{\partial x}}_{\text {migration }}
$$

To solve Eq. A.1 in the time domain (second derivative) the finite difference approximation method was used.

The CCM was divided into finite distance elements $\Delta x$ (as shown in Figure 11) and with boundary conditions (initial concentrations) assumed based on experimental data; the fluxes were calculated for the whole domain according to Eq. A.2.

$$
\begin{aligned}
J_{i}= & -D_{i}\left(\frac{c_{i-1}-c_{i}}{\Delta x}+\frac{c_{i+1}-c_{i}}{\Delta x}\right)-u_{m} c_{i}\left(\frac{\varphi_{i-1}-\varphi_{i}}{\Delta x}\right. \\
& \left.+\frac{\varphi_{i+1}-\varphi_{i}}{\Delta x}\right)
\end{aligned}
$$

Having fluxes calculated for all elements, the change of concentration over time $\Delta t$ was calculated.

$$
\Delta c_{i}(t)=c_{i . t-1}+J_{i, t} \cdot \frac{\partial t}{\partial x}
$$

Setting the time constant low enough enables to obtain a good approximation. Depending on the simulated case, the parameter $\Delta t$ was adjusted to ensure stability of the simulation. For the case where migration forces were present and the phenomena were occurring relatively fast the time constant was set to $0.1 \mathrm{~ms}$. For the case where only diffusion mechanism was present, the time constant was $1 \mathrm{~ms}$. All the equations were solved using in house developed python code.

\section{ORCID}

Mateusz Zlobinski (iD https://orcid.org/0000-0001-7365-7757

Lorenz Gubler (iD https://orcid.org/0000-0002-8338-6994

Pierre Boillat (iD https://orcid.org/0000-0002-5683-8086

\section{References}

1. A. Weiß, A. Siebel, M. Bernt, T.-H. Shen, V. Tileli, and H. A. Gasteiger, J. Electrochem. Soc., 166, F487 (2019).

2. K.-M. Mangold, ChemSusChem, 2, 781 (2009).

3. R. Winkler-Goldstein and A. Rastetter, "Power to gas: the final breakthrough for the hydrogen economy?" Green, 3, 69 (2013).

4. B. Bensmann, R. Hanke-Rauschenbach, G. Müller-Syring, M. Henel, and K. Sundmacher, Appl. Energy, 167, 107 (2016).

5. M. Götz, J. Lefebvre, F. Mörs, A. McDaniel Koch, F. Graf, S. Bajohr, R. Reimert, and T. Kolb, Renewable Energy, 85, 1371 (2016).

6. A. Buttler and H. Spliethoff, Renew. Sustain. Energy Rev., 82, 2440 (2018).

7. T. J. Schildhauer and S. M. A. Biollaz, CHIMIA International Journal for Chemistry, 69, 603 (2015)

8. A. Albert, A. O. Barnett, M. S. Thomassen, T. J. Schmidt, and L. Gubler, ACS Applied Materials \& Interfaces, 7, 22203 (2015).

9. A. Skulimowska, M. Dupont, M. Zaton, S. Sunde, L. Merlo, D. J. Jones, and J. Rozière, Int. J. Hydrogen Energy, 39, 6307 (2014).

10. C. K. Mittelsteadt and J. A. Staser, Polymer Science: A Comprehensive Reference, ed. K. Matyjaszewski and M. Möller (Elsevier, Amsterdam) p. 849 (2012).

11. P. Lettenmeier, S. Kolb, F. Burggraf, A. S. Gago, and K. A. Friedrich, J. Power Sources, 311, 153 (2016).

12. P. Lettenmeier, S. Kolb, N. Sata, A. Fallisch, L. Zielke, S. Thiele, A. S. Gago, and K. A. Friedrich, Energy \& Environmental Science, 10, 2521 (2017).

13. H. Ito, T. Maeda, A. Nakano, A. Kato, and T. Yoshida, Electrochim. Acta, 100, 242 (2013).

14. S. A. Grigoriev, P. Millet, S. A. Volobuev, and V. N. Fateev, Int. J. Hydrogen Energy, 34, 4968 (2009).

15. H. Ito, T. Maeda, A. Nakano, C. M. Hwang, M. Ishida, A. Kato, and T. Yoshida, Int. J. Hydrogen Energy, 37, 7418 (2012).

16. Z. Kang et al., Int. J. Hydrogen Energy, 43, 14618 (2018).

17. Z. Kang, J. Mo, G. Yang, S. T. Retterer, D. A. Cullen, T. J. Toops, J. B. Green Jr, M. M. Mench, and F.-Y. Zhang, Energy \& Environmental Science, 10, 166 (2017)

18. J. Mo, R. R. Dehoff, W. H. Peter, T. J. Toops, J. B. Green, and F.-Y. Zhang, Int. J. Hydrogen Energy, 41, 3128 (2016).

19. E. Oakton, D. Lebedev, A. Fedorov, F. Krumeich, J. Tillier, O. Sereda, T J. Schmidt, and C. Copéret, New J. Chem., 40, 1834 (2016).

20. E. Oakton, D. Lebedev, M. Povia, D. F. Abbott, E. Fabbri, A. Fedorov, M. Nachtegaal, C. Copéret, and T. J. Schmidt, ACS Catal., 7, 2346 (2017).

21. D. Lebedev et al., Chem. Mater., 29, 5182 (2017).

22. D. F. Abbott, D. Lebedev, K. Waltar, M. Povia, M. Nachtegaal, E. Fabbri, C. Copéret, and T. J. Schmidt, Chem. Mater., 28, 6591 (2016).

23. H.-S. Oh, H. N. Nong, T. Reier, M. Gliech, and P. Strasser, Chem. Sci., 6, 3321 (2015).

24. K. E. Ayers, J. N. Renner, N. Danilovic, J. X. Wang, Y. Zhang, R. Maric, and H. Yu, Catal. Today, 262, 121 (2016).

25. U. Government, (2011), DOE Technical Targets fo Hydrogen Production from ElectrolysisU.S. Department of Energy (DOE)Washingtonhttps://www.energy.gov/ eere/fuelcells/doe-technical-targets-hydrogen-production-electrolysis.

26. M. Schalenbach, M. Carmo, D. L. Fritz, J. Mergel, and D. Stolten, Int. J. Hydrogen Energy, 38, 14921 (2013).

27. P. Millet, N. Mbemba, S. A. Grigoriev, V. N. Fateev, A. Aukauloo, and C. Etiévant Int. J. Hydrogen Energy, 36, 4134 (2011). 
28. S. A. Grigoriev, V. I. Porembskiy, S. V. Korobtsev, V. N. Fateev, F. Auprêtre, and P. Millet, Int. J. Hydrogen Energy, 36, 2721 (2011).

29. B. Bensmann, R. Hanke-Rauschenbach, I. K. P. Arias, and K. Sundmacher, Electrochim. Acta, 110, 570 (2013).

30. F. Barbir, Sol. Energy, 78, 661 (2005)

31. U. Babic, M. Suermann, F. N. Büchi, L. Gubler, and T. J. Schmidt, J. Electrochem Soc., 164, F387 (2017)

32. S. Sun, Z. Shao, H. Yu, G. Li, and B. Yi, J. Power Sources, 267, 515 (2014).

33. L. Zhang, X. Jie, Z.-G. Shao, X. Wang, and B. Yi, J. Power Sources, 241, 341 (2013).

34. C. Rakousky, U. Reimer, K. Wippermann, M. Carmo, W. Lueke, and D. Stolten, J. Power Sources, 326, 120 (2016).

35. X. Wang, L. Zhang, G. Li, G. Zhang, Z.-G. Shao, and B. Yi, Electrochim. Acta, 158, 253 (2015)

36. U. Babic, M. Zlobinski, T. J. Schmidt, P. Boillat, and L. Gubler, J. Electrochem Soc., 166, F610 (2019).

37. F. N. Büchi, M. Inaba, and T. J. Schmidt, Polymer Electrolyte Fuel Cell Durability (Springer, New York) (2009).

38. J. Mo, S. M. Steen, F.-Y. Zhang, T. J. Toops, M. P. Brady, and J. B. Green, Int. J. Hydrogen Energy, 40, 12506 (2015).
39. Q. Feng, X. Z. Yuan, G. Liu, B. Wei, Z. Zhang, H. Li, and H. Wang, J. Power Sources, 366, 33 (2017).

40. M. Suermann, K. Takanohashi, A. Lamibrac, T. J. Schmidt, and F. N. Büchi, J. Electrochem. Soc., 164, F973 (2017).

41. U. Stuhr, H. Spitzer, J. Egger, A. Hofer, P. Rasmussen, D. Graf, A. Bollhalder, M. Schild, G. Bauer, and W. Wagner, Nucl. Instrum. Methods Phys. Res., Sect. A, $\mathbf{5 4 5}, 330$ (2005).

42. P. Boillat, Advanced characterization of polymer electrolyte fuel cells using high resolution neutron imaging (ETH, Zurich) (2009).

43. V. F. Sears, Neutron News, 3, 26 (1992)

44. Y. Lin, Q. Lu, F. Song, L. Yu, A. K. Mechler, R. Schlögl, and S. Heumann, Angew. Chem. Int. Ed., 58, 8917 (2019).

45. K. Jetsrisuparb, H. B. Youcef, A. Wokaun, and L. Gubler, J. Membr. Sci., 450, 28 (2014).

46. A. Baker, S. Komini Babu, R. Mukundan, S. Advani, A. Prasad, D. Spernjak, and R. L. Borup, Cerium Ion Mobility and Diffusivity Rates in Perfluorosulfonic Acid Membranes Measured via Hydrogen Pump Operation, 164, F1272 (2017).

47. J. Ye and K. Doblhofer, Ber. Bunsenges. Phys. Chem., 92, 1271 (1988). 